\title{
Towards higher accuracy and better frequency response with standard multi-hole probes in turbulence measurement with remotely piloted aircraft (RPA)
}

\author{
N. Wildmann, S. Ravi, and J. Bange \\ Center for Applied Geoscience, Eberhard-Karls-Universität Tübingen, Tübingen, Germany \\ Correspondence to: N. Wildmann (norman.wildmann@uni-tuebingen.de)
}

Received: 8 August 2013 - Published in Atmos. Meas. Tech. Discuss.: 14 November 2013

Revised: 13 February 2014 - Accepted: 26 February 2014 - Published: 22 April 2014

\begin{abstract}
This study deals with the problem of turbulence measurement with small remotely piloted aircraft (RPA). It shows how multi-hole probes (MHPs) can be used to measure fluctuating parts of the airflow in flight up to $20 \mathrm{~Hz}$. Accurate measurement of the transient wind in the outdoor environment is needed for the estimation of the 3-D wind vector as well as turbulent fluxes of heat, momentum, water vapour, etc. In comparison to an established MHP system, experiments were done to show how developments of the system setup can improve data quality. The study includes a re-evaluation of the pneumatic tubing setup, the conversion from pressures to airspeed, the pressure transducers, and the data acquisition system. In each of these fields, the steps that were taken lead to significant improvements. A spectral analysis of airspeed data obtained in flight tests shows the capability of the system to measure atmospheric turbulence up to the desired frequency range.
\end{abstract}

\section{Introduction}

In many applications multi-hole probes (MHPs) serve the purpose of measuring the flow angle and speed of an airstream. They are commonly used in wind-tunnel and road tests for the automotive industry (Zimmer et al., 2001) as well as in airborne measurements (Crawford and Dobosy, 1992). Many different designs and calibration techniques can be found in literature (Telionis et al., 2009; Sumner, 2000; Pfau et al., 2002; Lemonis et al., 2002). The minimum number of holes that are used for three dimensional flow measurement is four, while probes with five holes are common and seven-hole probes can also be found. With increasing number of holes, the range of the angle of incidence that can still be measured with the probe increases. There are also probes with only one pressure port, which is constantly turned inside the probe (Schlienger et al., 2002). The shape of the probe (conical, hemispherical or faceted) has an effect on the maximum incidence angle as well as on the sensitivity regarding Reynolds number changes (Telionis et al., 2009), due to the different points of flow separation. In airborne meteorology, the MHP made by Goodrich Sensor Systems (Rosemount, 1982) has been the most commonly used probe for measurements in the atmospheric boundary layer. Using flight calibration maneuvers, these MHPs can be used for wind measurement on-board manned aircraft (Friehe et al., 1996; Khelif et al., 1999). The development of the BAT probe (Crawford and Dobosy, 1992) enabled the measurement of the turbulent heat flux by combining fast temperature sensors with the existing system.

Within the last decade, RPASs (remotely piloted air systems) have become more and more affordable and suitable for atmospheric measurements and some have also been equipped with MHPs (Spieß et al., 2007; van den Kroonenberg et al., 2008; Thomas et al., 2012; Martin and Bange, 2014). The big advantage compared to manned aircraft is the decreased disturbance of the airflow by the aircraft, due to the smaller wingspan and wing load, which leads to smaller upwash (Crawford et al., 1996) and the reduced overall size, which decreases the disturbance of turbulence measurements according to Wyngaard et al. (1985). Higher flexibility and lower operating cost are other major advantages with small RPAS. The Meteorological Mini Aerial Vehicle $\left(\mathrm{M}^{2} \mathrm{AV}\right)$ is 
one of such RPAS and the measurement technique that was used in this system will be referred to as a benchmark in this study. New developments made as part of this study will be compared to the $\mathrm{M}^{2} \mathrm{AV}$ where possible. Since the turbulent wind vector and all turbulent flux measurements are strongly dependent on the measurement of airflow angles and true airspeed, a critical analysis of the systematic errors and sources for noise in the measurement with a MHP will be conducted. This analysis includes the complete measurement chain from the pneumatic setup of the probe and the pressure transducers until the sampling of the data.

The meteorological wind vector $\boldsymbol{v}$ (i.e. the wind vector in the earth's orthonormal, meteorological coordinate system) can be calculated from navigation, flow and attitude measurement aboard a research aircraft using

$\boldsymbol{v}=\boldsymbol{v}_{\mathrm{gs}}+\mathbf{M}_{\mathrm{mf}}\left(\boldsymbol{v}_{\mathrm{tas}}+\boldsymbol{\Omega} \times \boldsymbol{s}_{p}\right)$

(Williams and Marcotte, 2000). The ground-speed vector $\boldsymbol{v}_{\mathrm{gs}}$ describes the movement of the origin of the aircraft-fixed coordinate system (index $\mathrm{f}$ ) with respect to the earth's surface and is determined using the on-board navigation system. Aboard an RPA the latter is usually a combination of an inertial measurement unit (IMU) and a global navigation satellite system (GNSS). The determination of the ground speed $\boldsymbol{v}_{\mathrm{gs}}$ and the rotation into the earth's coordinate system $\mathbf{M}_{\mathrm{mf}}$ using the Eulerian angles are not subject of the present study, and are described in literature (Haering, 1990; Leise and Masters, 1993; Boiffier, 1998; van den Kroonenberg et al., 2008; Bange, 2009).

The true-airspeed vector $\boldsymbol{v}_{\text {tas }}$ is the flow vector measured by an in situ flow probe, in this study a MHP, preferably mounted at the nose of the RPA. Thus $\boldsymbol{v}_{\text {tas }}$ is defined in the aircraft's coordinate system $f$. The location of the MHP in relation to the origin of the aircraft-fixed coordinate system $f$ is described by the lever-arm vector $\boldsymbol{s}_{p}=\left(x_{p}, y_{p}, z_{p}\right)$, which points from the origin of the aircraft system $f$ to the location of the MHP. The vector of angular rotation rates $\boldsymbol{\Omega}$ contains the angular velocities of the aircraft system $f$ related to the meteorological system $m$ and is among the primary output data of the IMU.

In the following we focus on the determination of the trueairspeed vector $\boldsymbol{v}_{\text {tas }}$ defined by

$\boldsymbol{v}_{\mathrm{tas}}=-\frac{\left|\boldsymbol{v}_{\mathrm{tas}}\right|}{\sqrt{1+\tan ^{2} \alpha+\tan ^{2} \beta}}\left(\begin{array}{c}1 \\ \tan \beta \\ \tan \alpha\end{array}\right)$,

(see also Lenschow, 1986; Leise and Masters, 1993; Williams and Marcotte, 2000; van den Kroonenberg et al., 2008; Bange, 2009) with angle of attack $\alpha$ (positive for air flow from below) and sideslip $\beta$ (positive for flow from starboard). All three variables $\alpha, \beta$, and $\left|v_{\text {tas }}\right|$ in Eq. (2) can be derived from MHP pressure measurements.

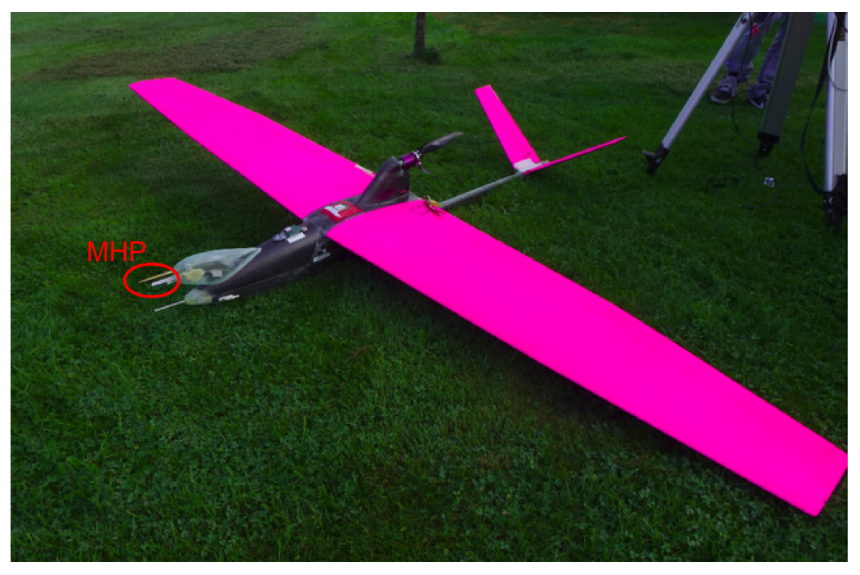

Fig. 1. Research RPA MASC. The position of the MHP approximately $15 \mathrm{~cm}$ in front of the fuselage nose tip is depicted with the red ellipse.

\section{Research RPA MASC}

At the University of Tübingen the research platform MASC (Multi-purpose Airborne Sensor Carrier) is operated and equipped with a MHP, fast temperature sensors, a barometer and a humidity sensor to enable the measurement of thermodynamic, turbulent scalars as well as the 3-D turbulent wind vector and turbulent fluxes of water vapour, sensible heat and momentum (Fig. 1 and Wildmann et al., 2013). The electrically powered motor-glider airplane with a wingspan between 2.60 and $3.40 \mathrm{~m}$ has a total weight of 5-7 kg depending on the battery and payload. Wind-tunnel experiments revealed that the fuselage and running pusher engine did not have a significant influence on the airflow at the location of the MHP. The aircraft is equipped with the autopilot ROCS (Research Onboard Computer System), which has been developed at the Institute for Flight Mechanics and Control (IFR) at the University of Stuttgart (Haala et al., 2011). The autopilot controls a constant airspeed of $24 \pm 1 \mathrm{~m} \mathrm{~s}^{-1}$ and constant altitude with a precision of $\pm 2 \mathrm{~m}$. Navigation to predefined waypoints is done relative to the take-off position. The flight tests that were performed to validate the results of this study were done with a MASC RPA.

\section{The probe}

\subsection{Mechanical design of the probe}

The MHP used at the University of Tübingen has a conical head, nine holes and was designed and manufactured at the Institute for Fluid Dynamics (ISM) of the Technische Universität Braunschweig, Germany. The arrangement of the holes can be seen in Fig. 2. In addition to the five holes on the cone, which are used to measure the flow angles, it has a ring with four holes in a $90^{\circ}$ offset pattern in front of it. These holes merge into one pressure port and provide a reference static 

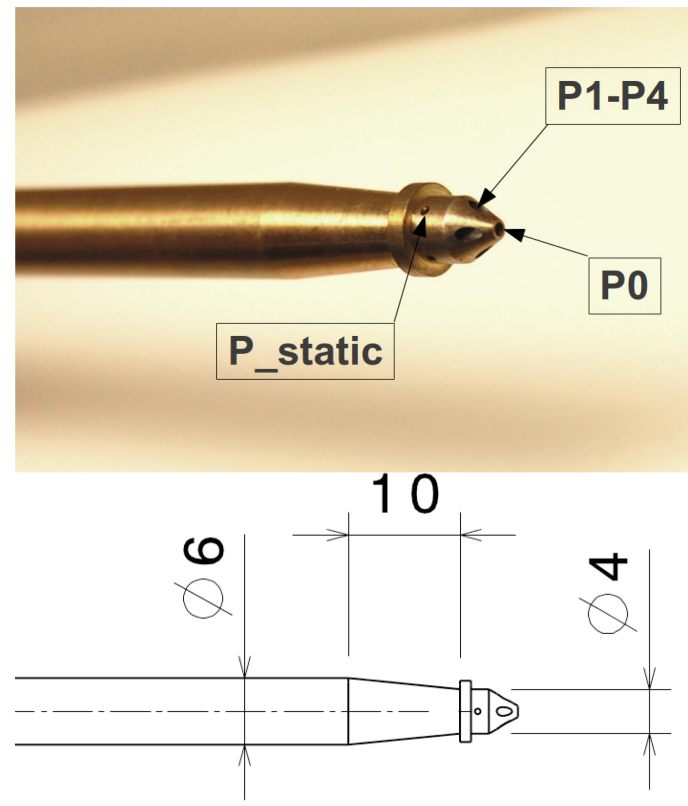

Fig. 2. Probe by ISM Braunschweig, picture and dimensions in millimetres.

pressure, which is less sensitive to the flow angle compared to normal static ports of a Prandtl sonde. This pressure port is then used in the standard calibration described in Sect. 2.2. The same probe was also used in the $\mathrm{M}^{2} \mathrm{AV}$. Figure 3 shows a computational fluid dynamic (CFD) simulation of the probe done with OpenFOAM at two different angles of attack.

\subsection{Differential pressure to flow angle conversion}

The conversion between differential pressures of the six pressure ports of the probe-to-flow angles and true airspeed is usually based on wind-tunnel calibration and can be done in several ways (see Sasangko, 1997; Bohn and Simon, 1975; Treaster and Yocum, 1979). A typical solution is a polynomial fit between normalized pressure differences and airflow angles, true airspeed and static pressure respectively. The ISM probe was intensively used in field campaigns (e.g. Martin et al., 2011; van den Kroonenberg et al., 2011; Spieß et al., 2007) with the $\mathrm{M}^{2} \mathrm{AV}$. Table 1 shows how dimensionless coefficients are defined from the pressures at the probe. The definitions on the left are taken from Bohn and Simon (1975), for an English summary see Spieß (2006). They are referred to as the $\mathrm{M}^{2} \mathrm{AV}$ conversion method in the following. The definition of the pressure ports and differential pressures is described in Figs. 4 and 5. The coefficients $k_{\alpha}$ and $k_{\beta}$ are directly calculated from the pressures at the MHP ports (see Table 1 for different methods to do so). Using a polynomial fit with coefficients that were determined in a wind-tunnel calibration, the angle of sideslip, angle of attack and the coefficients $k_{q}$ and $k_{p}$ can be calculated from $k_{\alpha}$ and $k_{\beta}$. To find dynamic and static pressure, the expressions for $k_{q}$ and $k_{p}$ in
Table 1 need to be solved for $q$ and $p$, respectively. A detailed description is given in Appendix A. The true airspeed as used in Eq. (2) has to be calculated using the measured total air temperature $T_{\text {tot }}$, the static pressure $p$ and the dynamic pressure $q$ :

$\left|\boldsymbol{v}_{\mathrm{tas}}\right|^{2}=2 c_{p} T_{\mathrm{tot}}\left[1-\left(\frac{p}{p+q}\right)^{\kappa}\right]$

with the Poisson number $\kappa=R / c_{p}$, where $R=$ $287 \mathrm{~J} \mathrm{~kg}^{-1} \mathrm{~K}^{-1}$ is the gas constant for dry air and $c_{p}=1005 \mathrm{~J} \mathrm{~kg}^{-1} \mathrm{~K}^{-1}$ is the specific heat for dry air.

In the $\mathrm{M}^{2} \mathrm{AV}$ conversion the ring pressure ports are used to find $q$ and $p$ to get a more angle-independent measurement. However, it was identified that in certain flight conditions the ring can cause problems for turbulence measurement, since the ring port pressure shows an increased noise level, which is induced by the probe itself. Figure 6 shows the result of measurements during the calibration procedure of the MHP in a jet wind tunnel with a turbulence intensity of about $1 \%$. At a constant airspeed of $22 \mathrm{~m} \mathrm{~s}^{-1}$ and angle of attack of $10^{\circ}$ the angle of sideslip $\beta$ was varied between -20 and $20^{\circ}$ in steps of $2^{\circ}$. Each position was held for $10 \mathrm{~s}$ and the standard deviation of the ring port pressure was measured. It can be seen that at certain angles of sideslip, the fluctuations of the measured pressure is higher than at other angles. This can be considered to be aerodynamic noise introduced by the probe.

To avoid measuring turbulence that is not primarily related to the atmosphere, a different pressure conversion method (see Table 1, right column) that avoids using the ring port pressure was tested. The method was initially proposed by Treaster and Yocum (1979) and is one of the most basic fivehole probe calibration methods. It only uses one front hole and four side holes.

The calibration results with the occurring nonlinearities are depicted in Figs. 7, 8 and 9. Below $10^{\circ}$ the nonlinearities are comparably small, but at higher angles the use of a ninth-order polynomial in calibration becomes necessary to represent the characteristics of the probe. Higher degree polynomials only marginally increase accuracy. The maximum deviation from the resulting polynomial in the calibration procedure is $0.47^{\circ}$ for $\alpha, 0.59^{\circ}$ for $\beta$ and $0.15 \mathrm{~m} \mathrm{~s}^{-1}$ for airspeed. These values also cover variations of wind-tunnel speed and inaccuracies in the angle settings.

Figure 10 shows the measurement of the airflow angles and true airspeed in one flight leg of $1000 \mathrm{~m}$ (including parts of the turns at the beginning and the end). The flight was done at late afternoon on 23 September close to the Lindenberg observatory of the German Meteorological Service. The flight altitude was $100 \mathrm{~m}$ above ground in an atmospheric boundary layer with weak stability.

The pressures from the five-hole probe were converted in both ways, with the $\mathrm{M}^{2} \mathrm{AV}$ method and with the MASC method, avoiding ring-port measurements. While the airflow angles do not show a difference, it can clearly be seen that true airspeed is much less noisy in the latter method. 

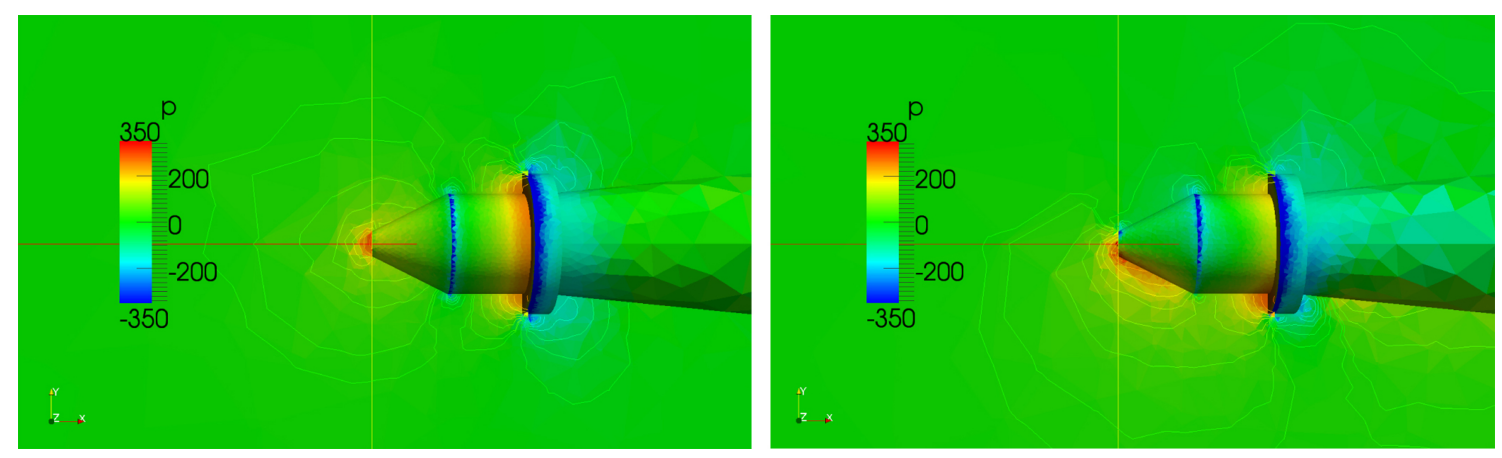

Fig. 3. OpenFOAM flow simulation around the probe tip at $24 \mathrm{~m} \mathrm{~s}^{-1}$ total airspeed at $0^{\circ}$ angle of sideslip in both figures, $0^{\circ}$ angle of attack in the left figure and $10^{\circ}$ angle of attack in the right figure. The colour scale shows differential pressure to the environment in pascals.
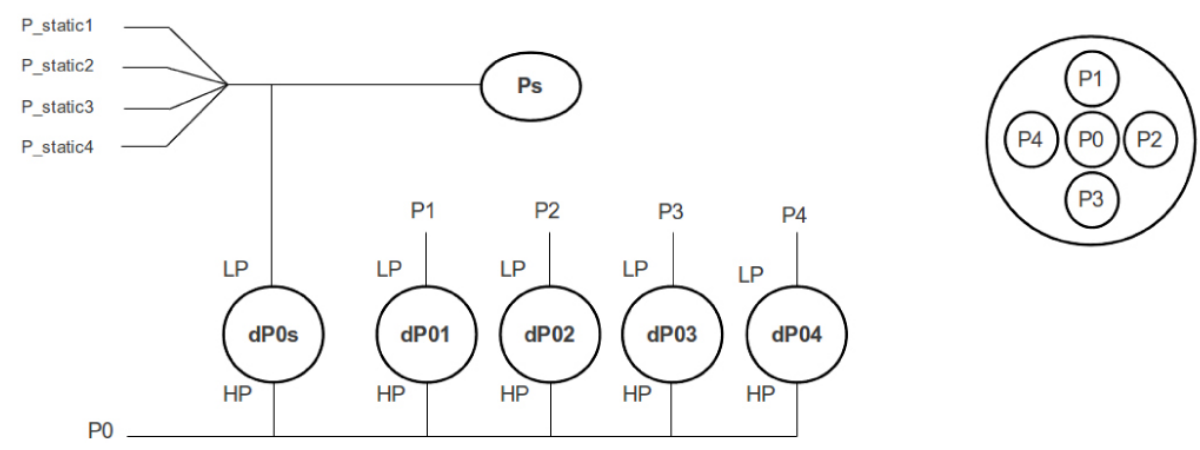

Fig. 4. Tubing system as used by the TU Braunschweig and described in Spieß et al. (2007) for the $M^{2}$ AV. The pressure transducer measurements $\mathrm{d} P 0 i$ are differential pressure readings of the low pressure port (LP) connected to the holes $P 1-P 4$ and the ring portholes $P_{\text {static }}$ compared to the high pressure port (HP), which in this case is the common port $P 0$. Ps represents a barometric pressure sensor.

The spectra of the velocities estimated through the $\mathrm{M}^{2} \mathrm{AV}$ (Fig. 11) shows that the noise introduced by the ring-pressure ports manifest as "white-noise" at higher frequencies, while the MASC method shows significantly reduced noise and the presence of the $k^{-\frac{5}{3}}$ slope (Kolmogorov distribution for locally isotropic turbulence in the inertial subrange).

It should be noted that the large difference between the two methods shows up explicitly at certain airflow angles, which were included in the presented time series. However, even though errors are smaller at other angle combinations, they can be completely avoided if the ring port pressure is not used for true airspeed calculation.

\section{Tubing response and calibration of the probe}

As transient velocities are of particular interest, the pneumatic dynamic response of tubing and transducer needs to be investigated to ensure measurements within a certain error band in the target frequency range. The tubing system within the MHP consists of a combination of a steel tube with an inner diameter of $0.7 \mathrm{~mm}$ and another tube of different material (e.g. PVC - polyvinyl chloride) and diameter. The dynamic response of the system depends not only on the length and diameter of the tubing, but also on the air volume inside the pressure transducers. The magnitude and phase response of tubing systems has been well investigated by Bergh and Tijdeman (1965). They derived theoretical estimates of the response of a single tube connected to either a single or multiple transducers connected in series with the variable tubing length, tubing diameter and transducer volume. Further studies by Semaan and Scholz (2012) investigated the validity of the model for short-tubing length and proved it suitable for tubing longer than $150 \mathrm{~mm}$; however, their model does not account for branched tubing systems.

Since differential pressures are required for airflow angle estimation, one strategy would be to connect the holes of a five-hole probe to pressure transducers and calculate the flow angles from the measured differential pressures as described in Spieß et al. (2007) for the $\mathrm{M}^{2} \mathrm{AV}$. The schematic of such a setup is shown in Fig. 4. This setup has a strongly branched tubing system at the high pressure port of all transducers ( $P_{0}$ is branched six times), whereas the low pressure port is in most cases directly connected to one hole of the probe. This setup cannot be simulated by a simple model like the one described by Bergh and Tijdeman (1965).

Alternatively, the holes in the probe can be connected to the transducers in the manner presented in Fig. 5. This 


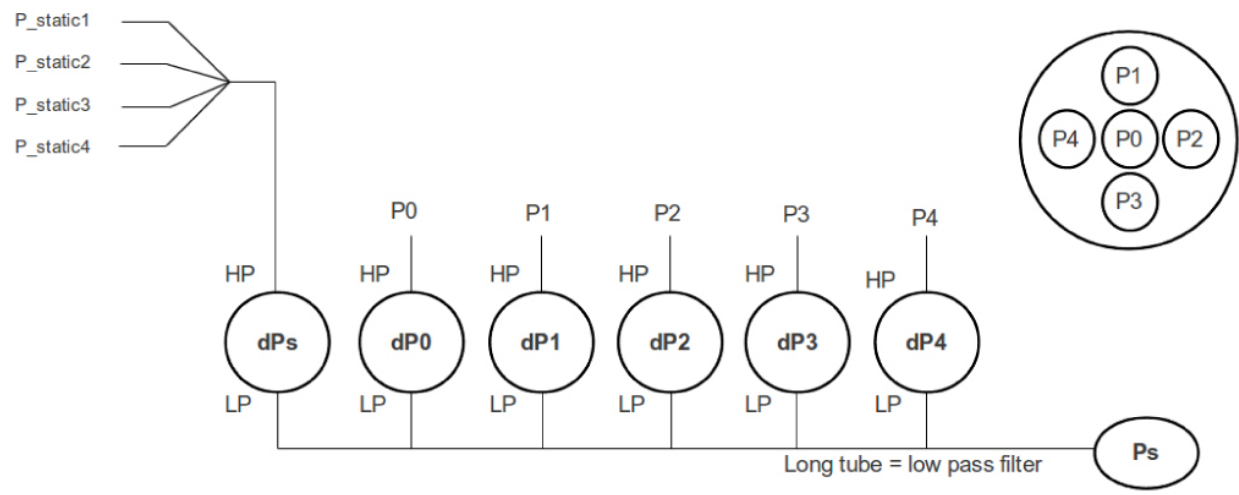

Fig. 5. Alternative tubing setup without branches as used in MASC. The pressure transducer measurements d $P i$ are differential readings of all single port pressures of the probe $\left(P 0-P 4\right.$ and $P_{\text {static }}$, high pressure, HP) compared to one common reference port (low pressure, LP).

Table 1. Comparison of two methods to define dimensionless coefficients for five-hole probe measurements.

\begin{tabular}{ccc}
\hline & Bohn et al. (1975) $\left(\mathrm{M}^{2} \mathrm{AV}\right)$ & Treaster and Yocum (1979) (MASC) \\
\hline$\Delta P$ & {$\left[\frac{1}{5} \sum_{i=0}^{4}\left(P_{i}-\frac{1}{5} \sum_{j=0}^{4} P_{j}\right)^{2}\right]^{\frac{1}{2}}+\left[P_{0}-\frac{1}{4} \sum_{i=1}^{4} P_{i}\right]$} & $\frac{\left(\mathrm{d} P_{1}+\mathrm{d} P_{2}+\mathrm{d} P_{3}+\mathrm{d} P_{4}\right)}{4}$ \\
$k_{\alpha}$ & $\frac{\mathrm{d} P_{01}-\mathrm{d} P_{03}}{\Delta P}$ & $\frac{\mathrm{d} P_{1}-\mathrm{d} P_{3}}{\mathrm{~d} P_{0}-\Delta P}$ \\
$k_{\beta}$ & $\frac{\mathrm{d} P_{02}-\mathrm{d} P_{04}}{\Delta P}$ & $\frac{\mathrm{d} P_{2}-\mathrm{d} P_{4}}{\mathrm{~d} P_{0}-\Delta P}$ \\
$k_{q}$ & $\frac{q-\mathrm{d} P_{0 s}}{\Delta P}$ & $\frac{\mathrm{d} P_{0}-q}{\mathrm{~d} P_{0}-\Delta P}$ \\
$k_{p}$ & $\frac{P_{\mathrm{s}}+\mathrm{d} P_{0 s}-p}{\Delta P}$ & $\frac{P_{\mathrm{s}}+\Delta P-p}{\mathrm{~d} P_{0}-\Delta P}$ \\
\hline
\end{tabular}

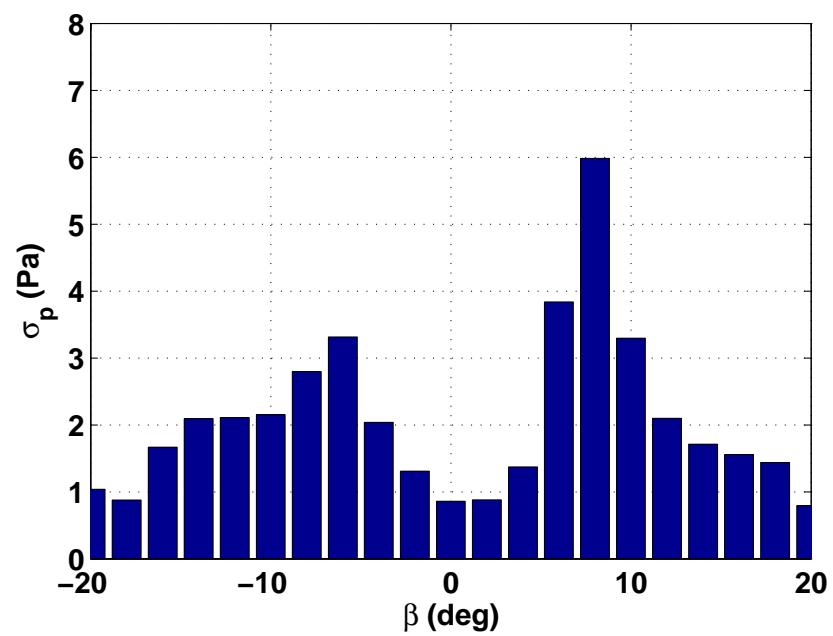

Fig. 6. Standard deviation of the pressure ports $P_{\text {static }}$ in front of the ring of the ISM probe during a wind-tunnel calibration. Angle of attack $10^{\circ}$, angle of sideslip shifted from -20 to $20^{\circ}$.

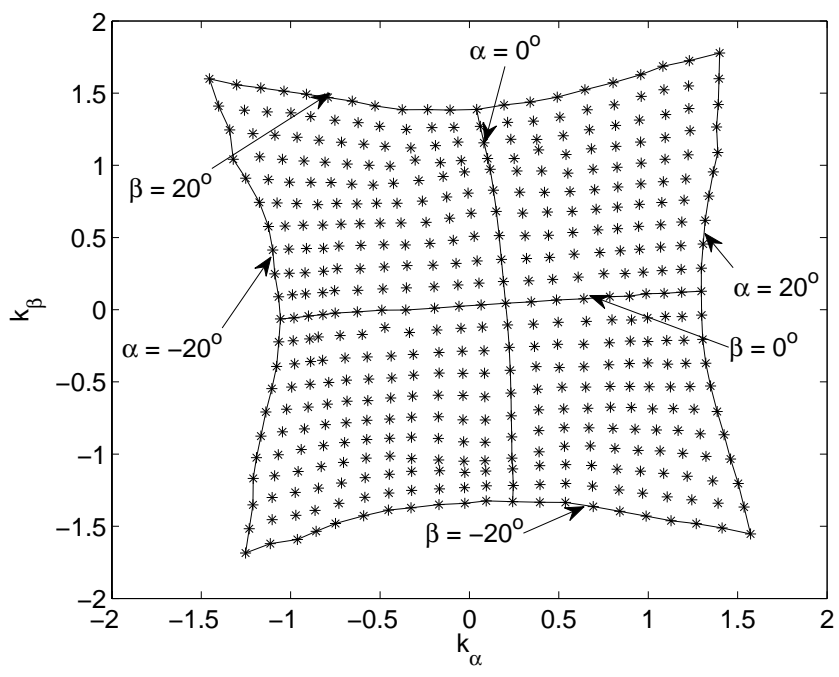

Fig. 7. Two-dimensional plot of $k_{\beta}$ over $k_{\alpha}$. The figure shows the nonlinearities that are larger for higher airflow angles $\alpha$ and $\beta$. 


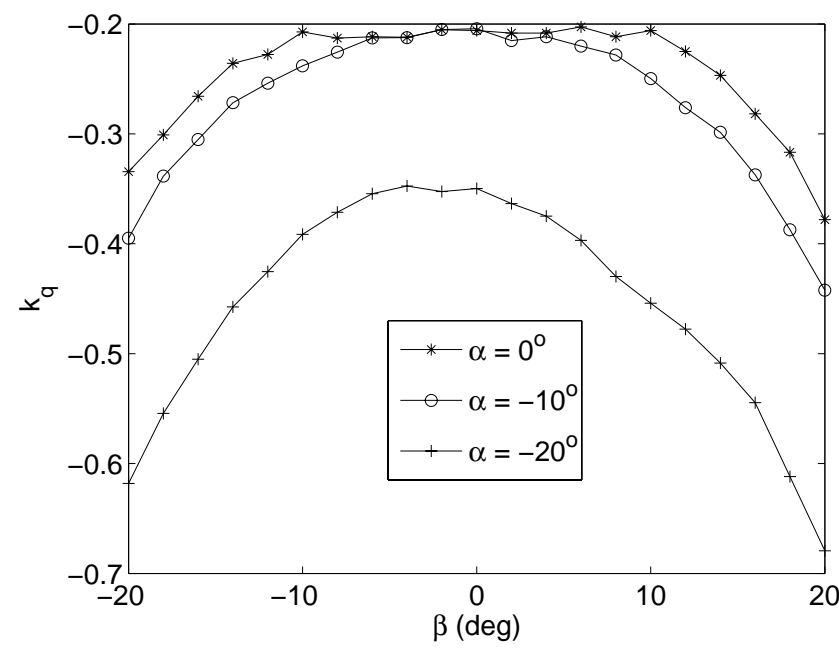

Fig. 8. Calibration coefficient $k_{q}$ for dynamic pressure against calibration angle $\beta$ for three attack angles $\alpha$.

method of tubing connection was used in MASC. The measured pressures can be converted to the same measurement as in the $\mathrm{M}^{2} \mathrm{AV}$ setup as follows:

$$
\begin{aligned}
\mathrm{d} P_{0 \mathrm{i}} & =\mathrm{d} P_{0}-\mathrm{d} P_{i} \\
\text { with } i & =1, \ldots, 4, s .
\end{aligned}
$$

To compare the $\mathrm{M}^{2} \mathrm{AV}$ and MASC setups with respect to the tubing system, the model of Bergh and Tijdeman cannot be used because it does not account for branches. Therefore, an experiment was set up to assess the response of the two different tubing strategies (see Fig. 12). What is depicted as "tubing under investigation" in the sketch is in a first experiment replaced with the $\mathrm{M}^{2} \mathrm{AV}$ 's branched tubing system as shown in Fig. 4 between the hole $P 0$ and the high pressure port (HP) of transducer $\mathrm{d} P 0 \mathrm{~s}$. In a second experiment, the tubing is replaced with MASC's single tube, as shown in Fig. 5 between hole $P 0$ and the HP port of transducer $\mathrm{d} P 0$. For all connections, PVC tube of a length similar to the actual setup that would be implemented in MASC (in this case $0.18 \mathrm{~m}$ ) was used. Instead of the connection to the $P 0$ hole of the probe, the free end of the tube is connected to a sealed volume attached to a speaker. A reference measurement was made by placing another transducer directly on the cabin wall without any tubing in between the pressure source and the transducer. The speaker was able to play sine waves with frequencies from 10 to several $100 \mathrm{~Hz}$. The measurement computer was logging the transducer output at a rate of $1 \mathrm{kHz}$. The maximum investigated frequency was $200 \mathrm{~Hz}$, which is higher than the sampling rate that is used in flight.

Initially, the response of the transducers themselves were tested. The transducers included sensors of the type P4VMini by the company AllSensors and sensors of type LBA by the company Sensortechnics. The P4V-Mini sensors work on the principle of a membrane that is displaced by the pressure

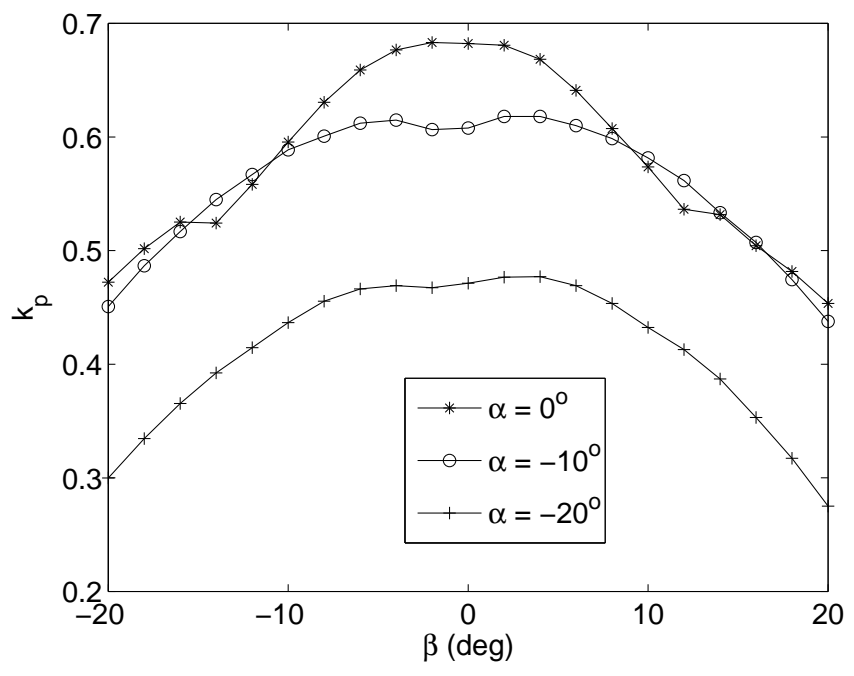

Fig. 9. Calibration coefficient $k_{p}$ for static pressure against calibration angle $\beta$ for three attack angles $\alpha$.

difference and its deflection is measured by piezoresistivity. The LBA sensors estimate pressure difference through a thermal mass-flow measurement.

To visualize the response of the pressure measurement system, the amplitude and phase response as the two parts of the transfer function $H$ of the system are calculated:

$H(\omega)=|H(\omega)| e^{i \phi(\omega)}$,

where $\omega$ is the angular frequency and $\phi$ the phase shift. The amplitude response is presented as the ratio between the standard deviation $\sigma$ of the tubing system being investigated and the reference:

$|H(\omega)|=\frac{\sigma_{P 0}(\omega)}{\sigma_{P_{\mathrm{ref}}}(\omega)}$.

To find the phase response of the system, the crosscorrelation function $\varrho_{P 0, P_{\text {ref }}}$ between the two sensors was calculated for each frequency and the time shift between the two signals needed for maximum correlation was estimated. This time shift was converted to a phase angle in the following manner:

$$
\begin{aligned}
\Delta t & =t\left(\max \mid \varrho_{P 0, P_{\text {ref }} \mid}\right), \\
\phi & =\Delta t \cdot \omega \cdot \frac{180}{\pi} .
\end{aligned}
$$

The tests with the P4V-Mini sensors showed considerable variations in the response of each individual transducer. Therefore, the experiment was carried out only with the LBA sensors by Sensortechnics. In Sect. 4 further reasons are given for choosing this type of sensor in future flight measurements. The amplitude and phase response of the two tubing systems are presented in Fig. 13. In the same figure, the theoretical response for the single tube of same length 

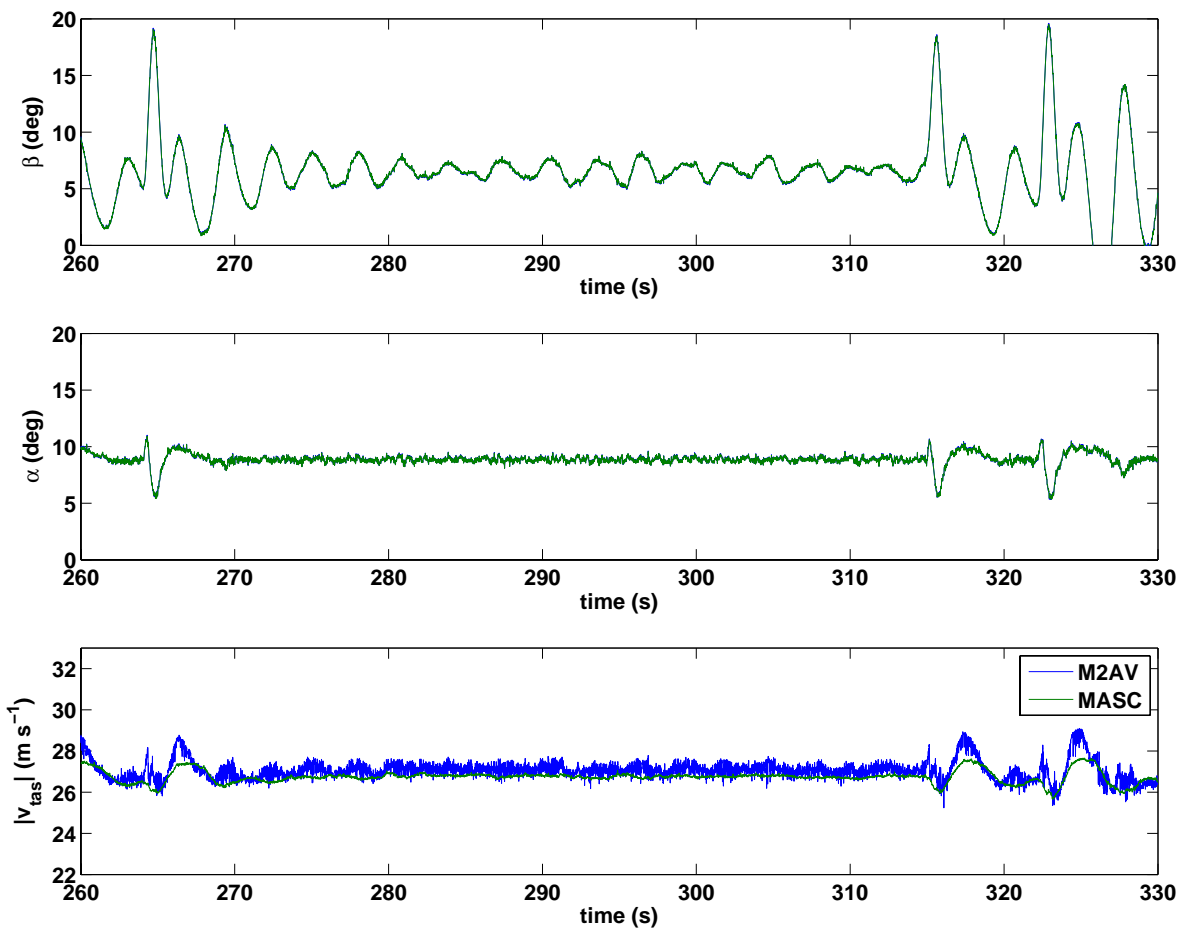

Fig. 10. True airspeed, measured with the five-hole probe and calculated with the $\mathrm{M}^{2} \mathrm{AV}$ and MASC methods respectively. Angle of attack throughout the leg approximately $10^{\circ}$; angle of sideslip approximately $8^{\circ}$. See text for flight conditions.

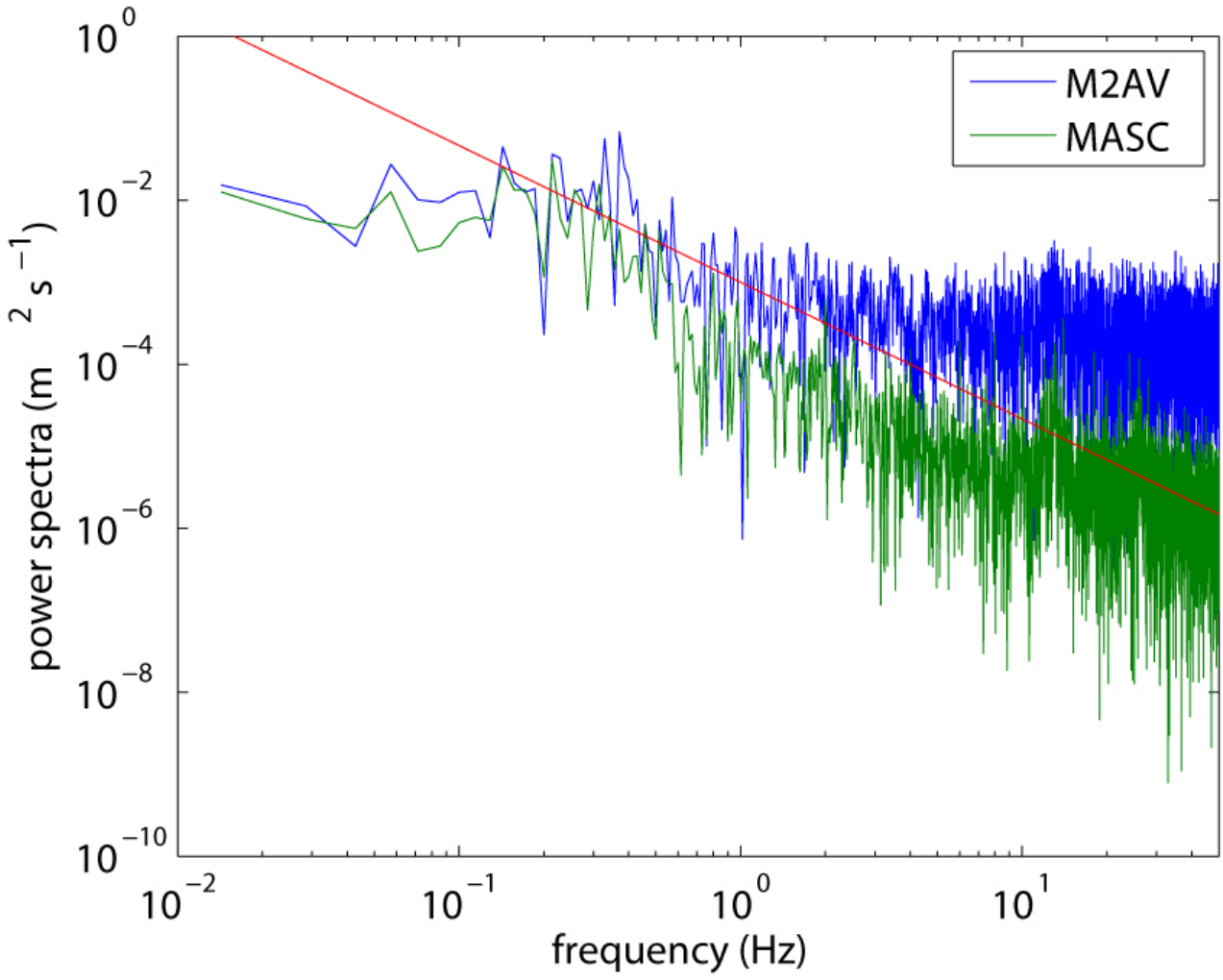

Fig. 11. Spectra of the true airspeed measurement in flight with standard calibration and new method. The red line shows the $k^{-\frac{5}{3}}$ slope. 


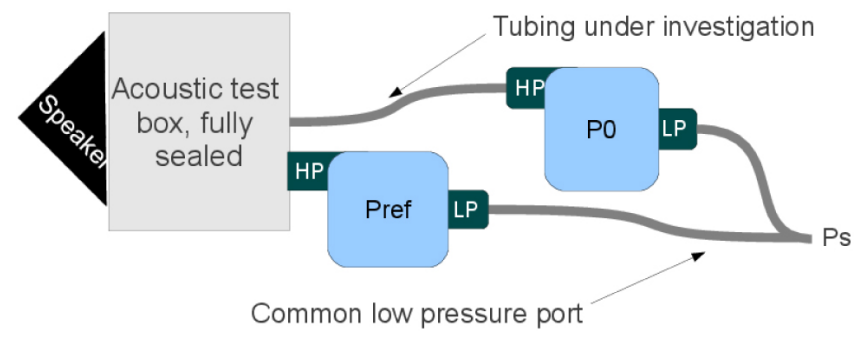

Fig. 12. Schematic drawing of the experiment to measure the tubing response. While the HP port of the reference transducer (Pref) is directly connected to the acoustic box, the HP port of the pressure measurement under investigation $(P 0)$ is connected with the necessary tubing of the real system. Ps is the common ambient pressure on the LP port of the transducers.

without branches as calculated with the Bergh and Tijdeman model is presented.

It can be seen that both tubing setups resemble oscillatory dynamic systems with at least one resonance frequency. The first resonant frequency of the $\mathrm{M}^{2} \mathrm{AV}$ system was found to be at around $80 \mathrm{~Hz}$, while it is out of the measurement range for the alternative setup. The damping factor of the $\mathrm{M}^{2} \mathrm{AV}$ setup is much higher than for the alternative setup, hence the resonance amplitude was much smaller. The phase response attenuates towards $-180^{\circ}$, which is characteristic for a second-order dynamical system.

It should be recalled that in the $\mathrm{M}^{2} \mathrm{AV}$ setup, one side of the differential transducers was connected to the side holes of the probe directly, while the other side of the transducers was connected to the front hole with a branch to five other transducers. In light of the acoustic tests performed here, it was identified that the tubing responses on either side of the transducer differ significantly. Though the two tubing systems have a nominally similar amplitude response, a phase shift $\varphi$ between each other would exist. Therefore an artificial signal $S_{\mathrm{m}}$ would be measured, which can be described as follows:

$$
\begin{aligned}
S_{\mathrm{m}} & =\sin \omega t-\sin (\omega t+\varphi), \\
& =\sin \omega t-\sin \omega t \cdot \cos \varphi+\cos \omega t \sin \varphi, \\
& =(1-\cos \varphi) \sin \omega t+\sin \varphi \cos \omega t,
\end{aligned}
$$

knowing that

$a \cdot \sin \omega t+b \cdot \cos \omega t=A \cos (\omega t-\alpha)$

with

$$
\begin{aligned}
A & =\sqrt{a^{2}+b^{2}}, \\
\tan \alpha & =\frac{b}{a},
\end{aligned}
$$

the artificial signal is

$$
\begin{aligned}
S_{\mathrm{m}} & =\sqrt{(1-\cos \varphi)^{2}+\sin \varphi^{2}} \cdot \cos \left[\omega t-\arctan \frac{\sin \varphi}{1-\cos \varphi}\right] \\
& =\sqrt{2(1-\cos \varphi)} \cdot \cos \left[\omega t-\cot ^{-1} \frac{\varphi}{2}\right] \\
& =2 \sin \frac{\varphi}{2} \cdot \cos \left[\omega t-\cot ^{-1} \frac{\varphi}{2}\right] .
\end{aligned}
$$

From Fig. 13, at $20 \mathrm{~Hz}$ the two tubing connections have a difference in phase shift of about $10^{\circ}$. This implies the transducer would measure a differential signal with an amplitude of $2 \sin \frac{10^{\circ}}{2}=0.174$ times the original absolute signal, which is added to the measurement and can thereby be defined as an error of almost $20 \%$.

To see the real behaviour of the two tubing strategies and the artificial signals that are measured due to phase shift effects, a setup equal to that present in the $\mathrm{M}^{2} \mathrm{AV}$ was tested. That is, both ends of a transducer were connected to the acoustic box whereby one port was connected to the box through a branch with five other transducers connected in parallel and the other port of the transducer was directly connected to the acoustic box via a $18 \mathrm{~cm}$ tube. In subsequent tests, both ports of the transducers were connected via $18 \mathrm{~cm}$ tubes to the acoustic box, this would resemble the alternate tubing strategy that is now being used on MASC. Ideally, as both ends of the transducers are connected to the same "source" (acoustic box), the pressures in the transducers should nullify one another and no pressures should be logged. The results of a time series measuring a sweep from 10 to $100 \mathrm{~Hz}$ (in steps of $10 \mathrm{~Hz}$ and a rest time of $10 \mathrm{~s}$ at each step) are shown in Fig. 14, left. The increase in amplitude of the pressure signal is not only due to an increasing phase shift, but also due to the increasing power of the speaker at the same gain setting. Figure 14, right, shows a normalized result for the measured frequency range, where the measured signal was divided by the prevailing pressure in the box that was measured with a second transducer. It can be seen that the relative error for $20 \mathrm{~Hz}$ is less than theoretically estimated, but it is also obvious that the effect can be observed in real measurements and can be avoided with the point-topoint tubing connections.

\section{The pressure transducers}

The volume of the pressure transducers adds to the pneumatic transfer function, and variation between different transducers can lead to a significantly different amplitude and phase response of the sensor at higher frequencies. Besides that, most pressure transducers are also sensitive to vibrations. In many MEMS (microelectromechanical system)-based differential pressure transducers, deformation of a membrane exposed to the applied pressure is measured by the means of piezoelectricity (in our study the sensor of type P4V-Mini, as used in the $\mathrm{M}^{2} \mathrm{AV}$ for example). The piezoelectric voltage 

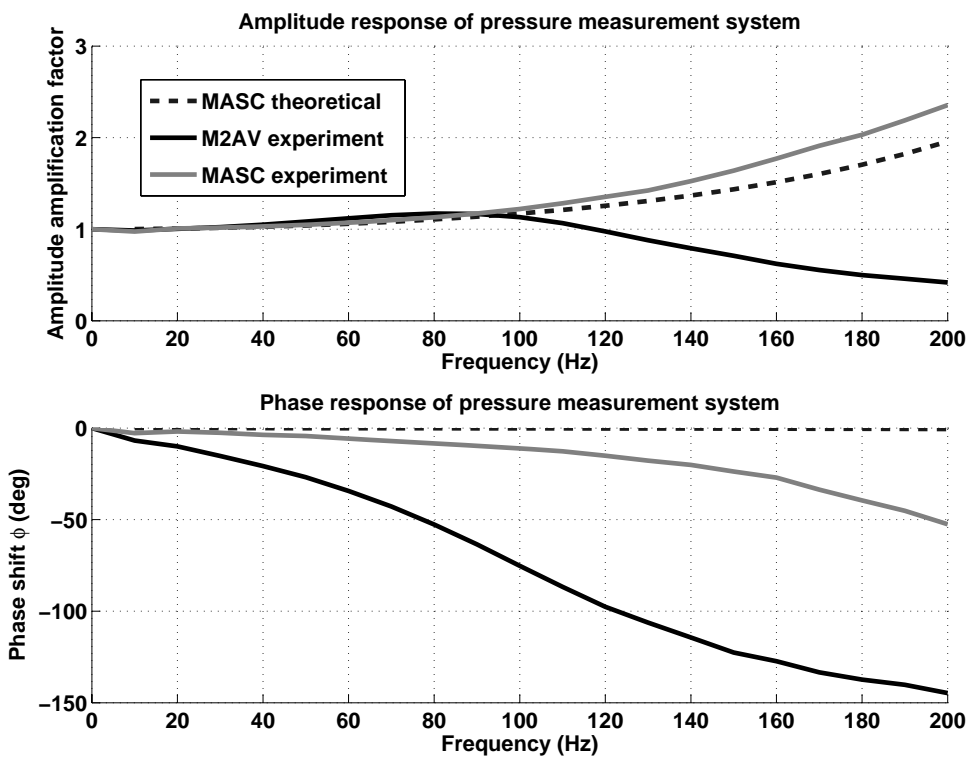

Fig. 13. Amplitude and phase response of the pressure measurement systems, including tubing, branches, transducer, etc. The MASC setup was investigated in an experiment (grey line) and theoretically with the Bergh and Tijdeman model (dashed line). The $\mathrm{M}^{2} \mathrm{AV}$ setup cannot be calculated with the model and thus is only investigated in an experiment (black line).
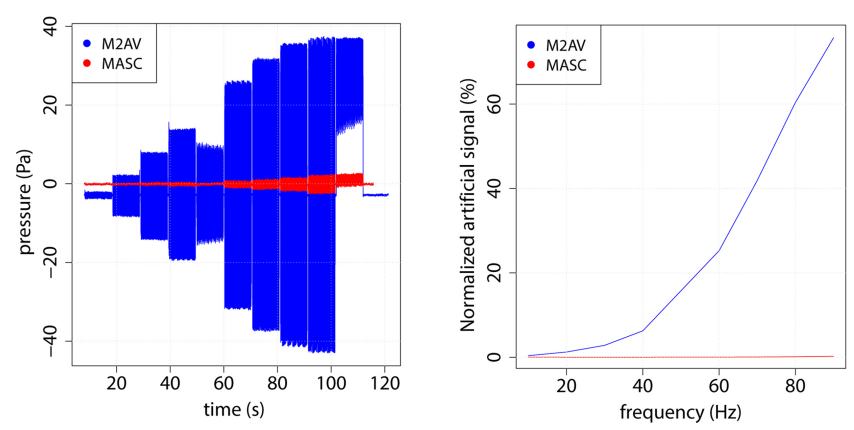

Fig. 14. Acoustic test of the MASC and the $\mathrm{M}^{2} \mathrm{AV}$ tubing system in comparison. Left: raw measurement of the transducers. Right: percentage of prevailing pressure that is measured as an artefact due to different phase shifts at the high and low pressure ports of the transducer.

is amplified and a voltage linear to the applied pressure is put out by the sensor. However, the membrane can also be deformed by accelerations perpendicular to the membrane surface. Since aircraft are always subject to vibrations and accelerations it is important to consider this effect in the pressure measurements when membrane-based pressure transducers are used. The way to reduce the errors made due to this effect can be to calibrate the sensors for the sensitivity regarding acceleration and measure the given accelerations in flight to subtract the acceleration-induced signal from the transducer output signal. A way to avoid the issue of sensitivity to accelerations completely is to choose a different measuring principle which is not based on a membrane deformation. A suitable alternative are sensors that work on thermal flow measurement (in our study the sensor of type LBA, as used in MASC). Figure 15 shows a comparison between a membrane-based sensor and a thermal flow sensor which were at the same time exposed to accelerations by mounting them on one solid board and applying shock accelerations in three different orientations. It can be seen that the accelerations in the direction perpendicular to the membrane orientation (here the $y$ direction) affect the membrane-based sensor, but not the thermal flow sensor. In the test, accelerations of up to $5 \mathrm{~m} \mathrm{~s}^{-2}$ were applied. Similar accelerations can be found in straight-leg flights with the MASC system. Other aircraft might have less or more vibration depending on the propulsion and flight dynamics. The resulting pressure transducer noise with amplitudes of up to $3 \mathrm{~Pa}$ adds to the higher frequency turbulence measurement and causes higher relative errors at lower turbulence intensity.

\section{Sampling and anti-aliasing}

So far, errors by aerodynamic and mechanical effects that affect the signal that is passed on by the pressure transducer were discussed. The next step in the measuring chain is to convert this analog $0-5 \mathrm{~V}$ signal from the pressure transducer to a digital signal and logging the data of all channels synchronously to one file. All data acquiring systems (DAQ) need to address the effect of aliasing in the measured frequency scales. Aliasing is critical in two ways: first, high frequency noise signals can alias into the sampled frequency range, if they are not filtered. Second, the signal 

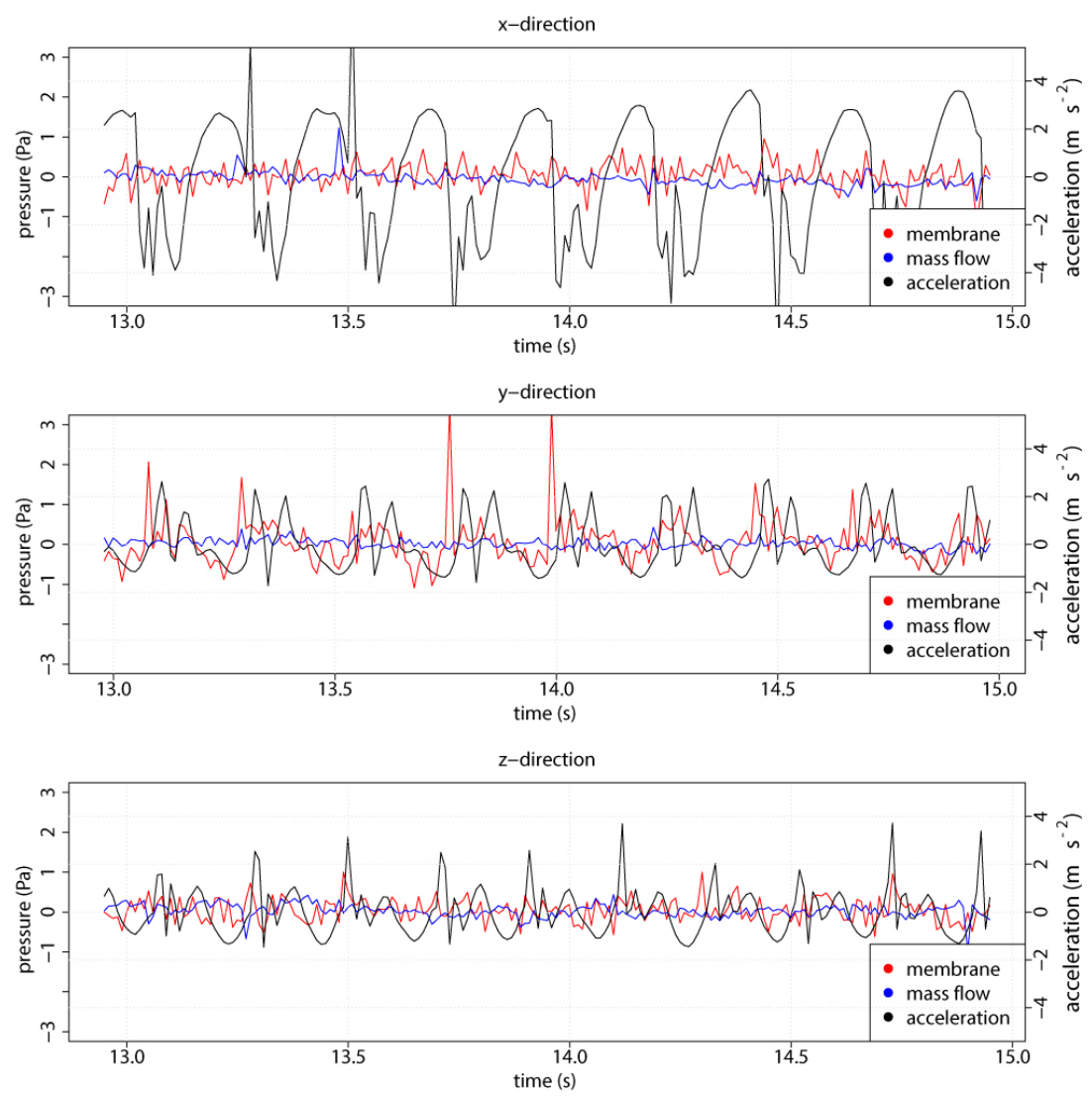

Fig. 15. Vibration/acceleration applied to pressure transducers in distinct directions

of the physical variable to be measured with frequencies slightly higher than half the sampling frequency can fold into the sampled frequency range and then lead to overestimates in the power of the signal at low frequencies. Commercial DAQ are generally unsuitable for RPA because they are either too heavy, too big or need too much power. The University of Tübingen developed the measuring computer AMOC (Airborne Meteorological Onboard Computer) in cooperation with the University of Applied Sciences OstwestfalenLippe. The computer is equipped with two STM32 microcontrollers, a 24 bit, 16 channel analog-to-digital converter, a telemetry interface, a SD (Secure Digital)-card slot for data logging and various other interfaces (see also Wildmann et al., 2013). To obtain reliable turbulence measurements within an error band of $10 \%$, an anti-aliasing filter was designed and implemented on the measuring computer which contains the following parts.

1. A first order analog filter (RC-low pass) with cut-off frequency at $160 \mathrm{~Hz}$ : only $50 \%$ of the original amplitude of signals with $160 \mathrm{~Hz}$ passes the filter, and only $10 \%$ of the signal at $500 \mathrm{~Hz}$. The amplitude response of the analog filter can be seen in Fig. 16 as a dashed blue line.
2. Oversampling of the signal at $500 \mathrm{~Hz}$ on-board the measuring computer: only signals above $500 \mathrm{~Hz}$ appear as aliases in the measured signal on-board the measuring computer. As described above, these signals are already damped to less than $10 \%$ of the original signal.

3. Digital moving average filter with cut-off frequency at $70 \mathrm{~Hz}$ in real-time on-board AMOC: the moving average filter is chosen because of its simple implementation, needing only little computing power in realtime processing and giving an optimal noise reduction while keeping sharp step responses (Smith, 1997). The rather poor performance of the filter in frequency separation is still good enough for the given task. From the red dashed line in Fig. 16, it can be seen that the filter still has a quasi-flat response at $10 \mathrm{~Hz}$ and still more than $91 \%$ of the signal amplitude is passed at $20 \mathrm{~Hz}$, while at $100 \mathrm{~Hz}$ only $25 \%$ passes and, thanks to the complementary analog filter, the response of signals above $150 \mathrm{~Hz}$ is always damped to a maximum of $6 \%$ of the original signal.

4. The log onto the SD-card at $100 \mathrm{~Hz}$ : logging at $100 \mathrm{~Hz}$ is another oversampling step to achieve anti-aliased 


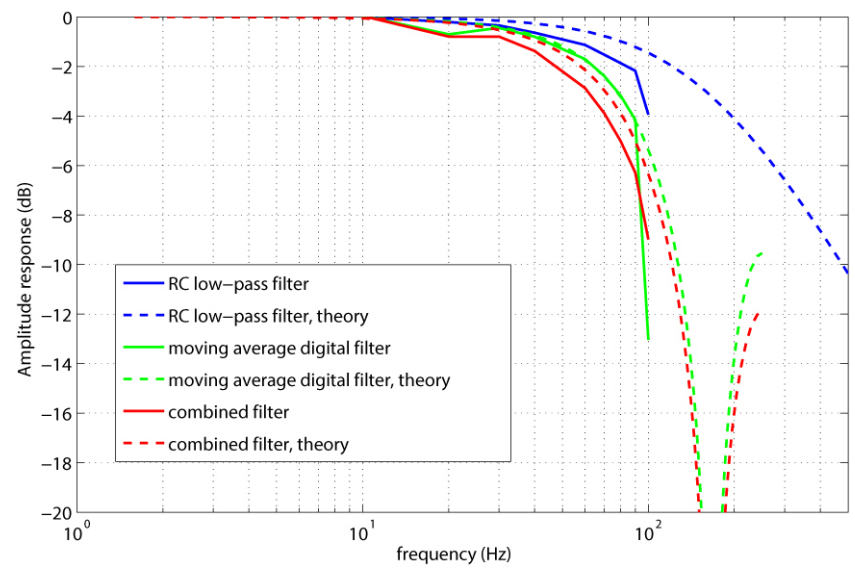

Fig. 16. Amplitude response of the applied filters in the analog channels of the MASC DAQ. The effective filter (red) is a combination of an analog RC low-pass filter (blue) and a digital moving average filter (green). The dashed lines represent the theoretical behaviour of the filters with the applied parameters. The solid lines represent measurements of the real sensor response in an acoustic box experiment.

data of up to at least $20 \mathrm{~Hz}$. Sampling at $100 \mathrm{~Hz}$, signals between 100 and $150 \mathrm{~Hz}$ can fold into the frequency range of up to $50 \mathrm{~Hz}$. The previous steps explained how these signals are already damped to less than $25 \%$. Frequencies above $150 \mathrm{~Hz}$ are damped to less than $6 \%$.

This means that in the frequency range from 0 to $50 \mathrm{~Hz}$ a maximum error caused by aliasing of $25 \%$ is theoretically possible. In reality, the measured signal is a turbulent flow, wherein the power of the signal decreases with increasing frequency (power law $\mathrm{k}^{-5 / 3}$ in the inertial subrange of locally isotropic turbulence, Kolmogorov, 1941). This means that the aliases naturally have a lower amplitude compared to the true signal at a specific frequency, which also means that the maximum error that was estimated is overestimated, except for unnatural noise signals. Note that electromagnetic noise typically begins at much higher frequencies that are filtered by the analog filter.

\section{Comparison of MASC and $\mathrm{M}^{2} \mathrm{AV}$ data}

In order to demonstrate that the design considerations in the airflow measurement system, as described above, do show the desired improvement in turbulence measurement, an analysis of the frequency response of the system in flight was carried out. Kolmogorov's theory of locally isotropic turbulence in the inertial subrange provides theoretical slopes of variance spectrum and structure function. If measured data is compared to this theory, the quality of turbulence measurement can be evaluated. Figure 17 shows the result of this analysis for true airspeed measurements. To prove that real
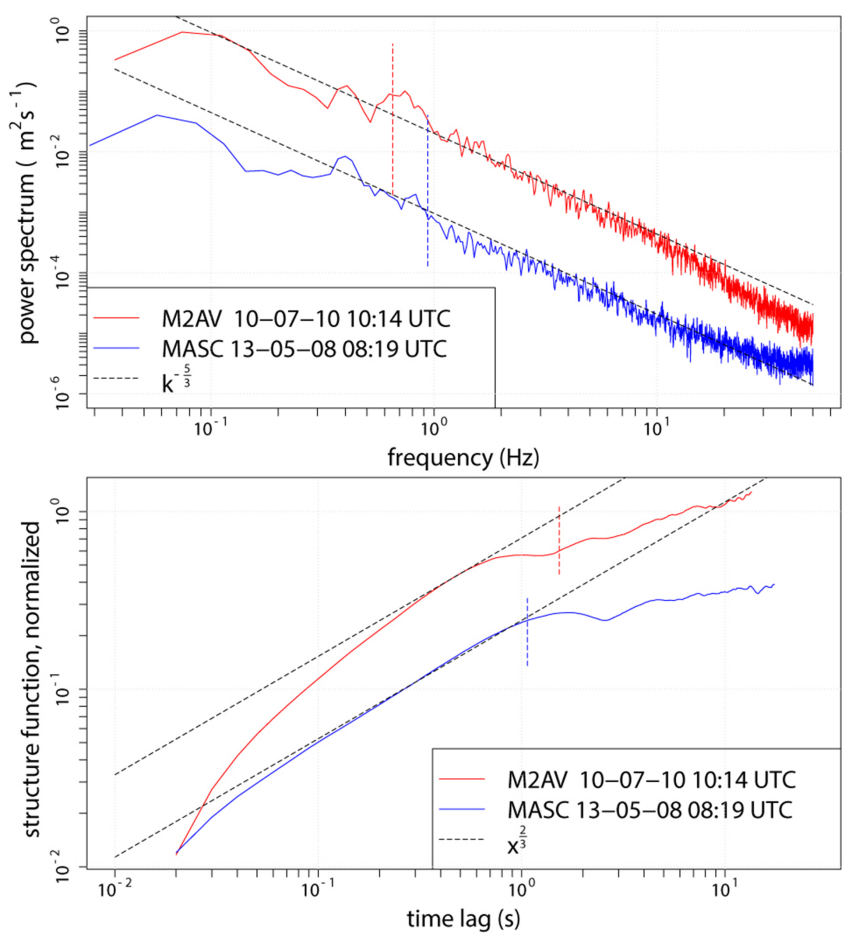

Fig. 17. A variance spectrum and a structure function of true airspeed measured with the MASC RPA in comparison to a measurement with the $\mathrm{M}^{2} \mathrm{AV}$ RPA. In both plots, the result is an average over 15 legs of $27 \mathrm{~s}$ each. The structure function is normalized by $2 \sigma^{2}$ and therefore dimensionless. In both plots, MASC results are shifted towards lower values for better readability. The dashed lines indicate an estimation of the entry point of the inertial subrange. See text for flight conditions.

enhancements compared to established measurement systems like the $\mathrm{M}^{2} \mathrm{AV}$ were achieved, the result is compared to measurements of the $\mathrm{M}^{2} \mathrm{AV}$ in very similar meteorological conditions. The $\mathrm{M}^{2} \mathrm{AV}$ flight was in summer on 10 July 2010. The MASC flight in late spring, 8 May 2013, both in the already mixed layer in the late morning at an altitude of 200 and $100 \mathrm{~m}$ respectively. It can be seen that the MASC system follows the theory very well up to $10 \mathrm{~Hz}$. Slight damping according to the theory in Sect. 5 can be observed at higher frequencies. According to the experiments that were done, comparing tubing strategy, pressure transducers and probe calibration, it would be expected that the $\mathrm{M}^{2} \mathrm{AV}$ system is subject to more noise. The data does not reflect this. Instead, in the structure function, a strong damping is observed in the system starting at a time lag of approximately $0.5 \mathrm{~s}$, which corresponds to turbulent signals with a frequency of $2 \mathrm{~Hz}$. This suggests that the noise was reduced by a low-pass filter in the pressure measurements of the probe. This cannot be ascertained in the absence of more information on the DAQ used in the $\mathrm{M}^{2} \mathrm{AV}$. However, it can be stated that the MASC MHP setup meets the desired frequency response better than the $\mathrm{M}^{2} \mathrm{AV}$ system. Analysis of seven more flights of 
the $\mathrm{M}^{2} \mathrm{AV}$ in campaigns between 2007 and 2011 were analysed and supported the findings.

\section{Conclusions}

It was shown in this study how a standard MHP can be optimized for turbulence measurements by following a few, easy steps. It is of high importance to know the frequency response of each piece in the measuring chain, starting with the pneumatic response of the MHP itself, the tubing and the pressure transducers. The common error of vibration sensitivity in membrane-based pressure transducers was discussed, and to avoid this effect we suggest to use thermal flow sensors instead. It was also shown how the data acquisition has to be optimized for nondisturbed turbulence measurement in the desired frequency range. The effect of antialiasing can be minimized by an appropriate filter design. Considering these points, precise measurements of mean flow and turbulent fluctuation of up to $20 \mathrm{~Hz}$ can be achieved with the given MHP and DAQ system. To use the MHP in RPA applications for wind and flux measurement, it has to be embedded into a measurement system consisting of the aircraft itself, inertial measurements and an autopilot in best case. Issues such as flow distortion by the fuselage and wings have to be discussed for each individual aircraft type (Crawford et al., 1996; Wyngaard et al., 1985). The fusion of airflow data with inertial measurements to calculate wind is already described by van den Kroonenberg et al. (2008).

Acknowledgements. The authors would like to thank the anonymous reviewers for their valuable comments and suggestions to improve the quality of the paper. We would furthermore like to thank Maximilian Ehrle and Markus Auer for their great job as safety pilots and Bernd Peters and the IAG Stuttgart for the support and time with the jet wind tunnel. The measuring equipment would not have been ready to work without the help of Jens Dünnermann and Burkhard Wrenger from the University of Applied Sciences Ostwestfalen-Lippe. We acknowledge the support from Dr. Ing. Peter Scholz at the University of Braunschweig for questions regarding the MHP design.

We acknowledge support by Deutsche Forschungsgemeinschaft and Open Access Publishing Fund of Tübingen University.

Edited by: S. Malinowski

\section{References}

Bange, J.: Airborne Measurement of Turbulent Energy Exchange Between the Earth Surface and the Atmosphere, Sierke Verlag, Göttingen, Germany, 174 pp., ISBN 978-3-86844-221-2, 2009.

Bergh, H. and Tijdeman, H.: Theoretical and Experimental Results for the Dynamic Response of Pressure Measuring Systems, vol. 238, National Luchten Ruimtevaartlaboratorium, Amsterdam, NL, 1965.
Bohn, D. and Simon, H.: Mehrparametrige Approximation der Eichräume und Eichflächen von Unterschall- bzw. Überschall-5Loch-Sonden, Archiv für technisches Messen + messtechnische Praxis, 42, 31-37, 1975.

Boiffier, J.-L.: The Dynamics of Flight - the Equations, Wiley, Chichester, UK, 1998.

Crawford, T. L. and Dobosy, R. J.: A Sensitive Fast-Response Probe to Measure Turbulence and Heat Flux from any Airplane, Bound.-Lay. Meteorol., 59, 257-278, 1992.

Crawford, T. L., Dobosy, R. J., and Dumas, E. J.: Aircraft Wind Measurement Considering Lift-Induced Upwash, Bound.-Lay. Meteorol., 80, 79-94, 1996.

Friehe, C. A., Burns, S. P., Khelif, D., and Song, X.: Meteorological and Flux Measurements from the NOAA WP3D Aircraft in TOGA COARE, in: 8th Conference on Air-Sea Interaction, J42J45, AMS, Atlanta, GA, 1996.

Haala, N., Cramer, M., Weimer, F., and Trittler, M.: Performance Test on UAV-Based Photogrammetric Data Collection, in: UAV-g (unmanned aerial vehicle in geomatics) Conference, Zurich, Switzerland, vol. 16-20, American Meteorological Society, 2011.

Haering, E. A.: Airdata Calibration of a High-Performance Aircraft for Measuring Atmospheric Wind Profiles, Tech. Mem. 101714, NASA, Edwards, CA, 24 pp, 1990.

Khelif, D., Burns, S. P., and Friehe, C. A.: Improved Wind Measurements on Research Aircraft, J. Atmos. Oceanic Technol., 16, 860-875, 1999.

Kolmogorov, A.: The Local Structure of Turbulence in Incompressible Viscous Fluid for Very Large Reynolds Numbers, Dokl. Akad. Nauk SSSR, 30, 299-303, reprint: Proc. R. Soc. Lond. A, 1991, 434, 9-13, 1941.

Leise, J. A. and Masters, J. M.: Wind Measurements from Aircraft, US Department of Commerce, National Oceanic and Atmospheric Administration, Aircraft Operation Center, Miami, Florida, USA, 1993.

Lemonis, G., Schmücker, M., and Struck, H.: A Fast Response Probe System for In-Flight Measurements of Atmospheric Turbulence, Aerospace Sci. Tech., 6, 233-243, 2002.

Lenschow, D. H.: Aircraft Measurements in the Boundary Layer, in: Probing the Atmospheric Boundary Layer, edited by Lenschow, D. H., 39-53, Amer. Meteorol. Soc., Boston, MA, 1986.

Martin, S. and Bange, J.: The Influence of Aircraft Speed Variations on Sensible Heat-Flux Measurements by Different Airborne Systems, Bound.-Lay. Meteorol., 150, 153-166, doi:10.1007/s10546-013-9853-7, 2014.

Martin, S., Bange, J., and Beyrich, F.: Meteorological profiling of the lower troposphere using the research UAV "M2AV Carolo", Atmos. Meas. Tech., 4, 705-716, doi:10.5194/amt-4-705-2011, 2011

Pfau, A., Schlienger, J., Kalfas, A. I., and Abhari, R. S.: Virtual Four Sensor Fast Response Aerodynamic Probe (FRAP), in: 16th Symposium on Measuring Techniques in Transonic and Supersonic Flow in Cascades and Turbomachines, Cambridge, UK, 2002.

Rosemount: Model 858 Flow Angle Sensors, Rosemount Inc., Minneapolis, MN, bulletin 1014, 1982.

Sasangko, H.: Rand- und Spaltströmungen in stark gestaffelten Verdichtergittern aus schwach gewölbten Profilen, Technische Universität Braunschweig, ZLR-Forschungsbericht, 01, 1997. 
Schlienger, J., Pfau, A., Kalfas, A. I., and Abhari, R. S.: Single Pressure Transducer Probe for 3D Flow Measurements, in: 16th Symposium on Measuring Techniques in Transonic and Supersonic Flow in Cascades and Turbomachines, Cambridge, UK, 2002.

Semaan, R. and Scholz, P.: Pressure correction schemes and the use of the Wiener deconvolution method in pneumatic systems with short tubes, Experiments in Fluids, 53, 829-837, 2012.

Smith, S. W.: The scientist and engineer's guide to digital signal processing, California Technical Publishing, San Diego, CA, USA, 1997.

Spieß, T.: A Contribution to Turbulence Measurements with Autonomous Micro Aerial Vehicles, Ph.D. thesis, Institute for Aerospace Systems, Techn. Univ. Braunschweig, Germany, 137 pp., 2006.

Spieß, T., Bange, J., Buschmann, M., and Vörsmann, P.: First Application of the Meteorological Mini-UAV "M2AV", Meteorol. Z. N. F., 16, 159-169, 2007.

Sumner, D.: Calibration Methods for a Seven-Hole Pressure Probe, in: Sixth Triennial International Symposium on Fluid Control, Measurement and Visualization (Flucome 2000), edited by: Laneville, A., Sherbrooke, Canada, 2000.

Telionis, D., Yang, Y., and Redinioti, O.: Recent developments in multi-hole probe ( $\mathrm{mhp})$ technology, in: 20th International Conference of Mechanical Engineering, Gramado, RS, Brazil, ABCM, 2009.

Thomas, R. M., Lehmann, K., Nguyen, H., Jackson, D. L., Wolfe, D., and Ramanathan, V.: Measurement of turbulent water vapor fluxes using a lightweight unmanned aerial vehicle system, Atmos. Meas. Tech., 5, 243-257, doi:10.5194/amt-5-243-2012, 2012.
Treaster, A. L. and Yocum, A. M.: The calibration and application of five-hole probes, ISA Trans., 18, 23-34, 1979.

van den Kroonenberg, A. C., Martin, T., Buschmann, M., Bange, J., and Vörsmann, P.: Measuring the Wind Vector Using the Autonomous Mini Aerial Vehicle $\mathrm{M}^{2} \mathrm{AV}$, J. Atmos. Oceanic Technol., 25, 1969-1982, 2008.

van den Kroonenberg, A. C., Martin, S., Beyrich, F., and Bange, J.: Spatially-averaged temperature structure parameter over a heterogeneous surface measured by an unmanned aerial vehicle, Bound.-Lay. Meteorol., 142, 55-77, 2011.

Wildmann, N., Mauz, M., and Bange, J.: Two fast temperature sensors for probing of the atmospheric boundary layer using small remotely piloted aircraft (RPA), Atmos. Meas. Tech., 6, 21012113, doi:10.5194/amt-6-2101-2013, 2013.

Williams, A. and Marcotte, D.: Wind Measurements on a Maneuvering Twin-Engine Turboprop Aircraft Accounting for Flow Distortion, J. Atmos. Oceanic Technol., 17, 795-810, 2000.

Wyngaard, J. C., Rockwell, L., and Friehe, C. A.: Errors in the Measurement of Turbulence Upstream of an Axisymmetric Body, J. Atmos. Oceanic Technol., 2, 605-614, 1985.

Zimmer, G., Alam, F., Watkins, S., and Peric, C.: Comparison of a High Blockage Wind Tunnel, an Open Jet Wind Tunnel and Onroad Testing with Respect to External Surface Pressures, in: SAE 2001 World Congress Detroit, MI, Technical Papers, 2001-011087, 2001. 


\section{Appendix A}

\section{Five-hole probe pressures to airflow vector conversion}

For a better understanding, a detailed step by step description of the measurement with a five-hole probe will be given here. The description needs to be divided into the wind-tunnel calibration procedure and the actual instantaneous measurement of the airspeed vector.

\section{A1 Wind-tunnel calibration}

A wind-tunnel calibration is essential for the measurement with a multi-hole probe. The goal of the wind-tunnel calibration is to find a relationship between the measured pressures $\mathrm{d} P_{i}$ and the airflow angles $\alpha$ and $\beta$. Besides this, the probe needs to be calibrated to measure the correct dynamic and static pressure at any airflow angle (within the calibration range). In order to make this fit robust against changes in airspeed (i.e. changes in Reynolds number), a polynomial fit is not directly applied to the raw pressure readings, but dimensionless coefficients are defined (see Table 1).

The presetting of the wind tunnel is a certain dynamic pressure $q$ and static pressure $p$, which should be continuously measured with an independent measuring system during the calibration routine. $k_{\alpha}$ and $k_{\beta}$ serve as the variables of the polynomial functions for $\alpha, \beta$, and $k_{p}$, and $k_{q} . k_{p}$ and $k_{q}$ can be understood as correction values for dynamic pressure and static pressure with regards to the airflow angle at the probe.

$$
\begin{aligned}
\alpha & =f_{\alpha}\left(k_{\alpha}, k_{\beta}\right) \\
\beta & =f_{\beta}\left(k_{\alpha}, k_{\beta}\right) \\
k_{p} & =f_{s}\left(k_{\alpha}, k_{\beta}\right) \\
k_{q} & =f_{q}\left(k_{\alpha}, k_{\beta}\right)
\end{aligned}
$$

The functions $f_{x}\left(k_{\alpha}, k_{\beta}\right)$ are arranged as a polynomial of order $m$ and the two variables:

$$
f_{x}\left(k_{\alpha}, k_{\beta}\right)=\sum_{i=0}^{m}\left(k_{\alpha}\right)^{i}\left[\sum_{j=0}^{m} X_{i j}\left(k_{\beta}\right)^{j}\right] \text {, }
$$

with $X_{i j}$ the coefficients $c_{\alpha, i j}, c_{\beta, i j}, c_{s, i j}$ and $c_{q, i j}$, for the estimation of $\alpha, \beta, k_{p}$ and $k_{q}$ respectively. To achieve a good accuracy with the polynomial fit, calibration with angle steps of $2^{\circ}$ is recommended. The calibration range for the MHP under investigation is suggested to be not larger than $20^{\circ}$ in all directions. A sufficiently large number of calibration settings yields four overestimated systems of linear equations, which can be presented in matrix notation:

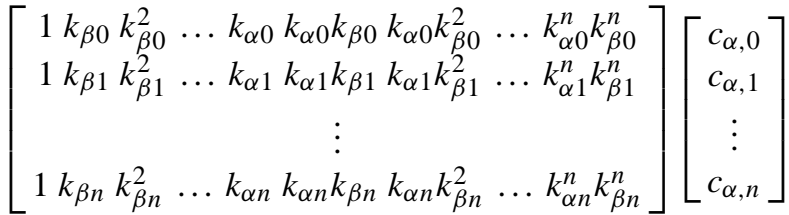

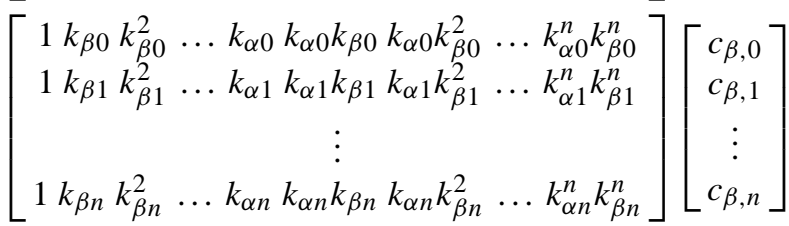

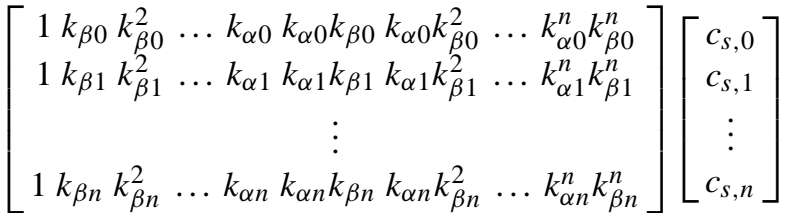

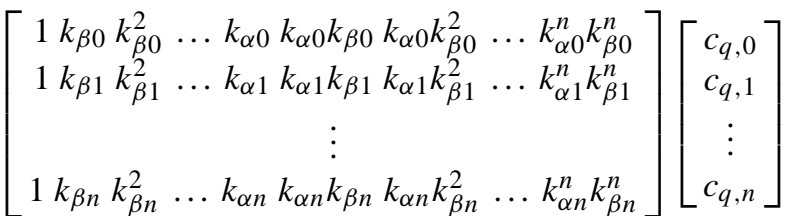

A solution for the coefficients $c$ can be found with a least squares method. For the coefficients $c_{\alpha, i}$ this would, for example, yield

$$
\begin{aligned}
\boldsymbol{\alpha} & =\mathbf{K} \cdot \boldsymbol{c}_{\alpha}, \\
S\left(\boldsymbol{c}_{\alpha}\right) & =\sum_{i=1}^{m}\left|\alpha_{i}-\sum_{j=1}^{n} K_{i j} c_{\alpha, j}\right|^{2}=\left\|\boldsymbol{\alpha}-\mathbf{K} \cdot \boldsymbol{c}_{\alpha}\right\|^{2}, \\
\hat{\boldsymbol{c}}_{\alpha} & =\underset{\boldsymbol{c}_{\alpha}}{\arg \min } S\left(\boldsymbol{c}_{\alpha}\right),
\end{aligned}
$$

where $S$ is the minimization criterion and $\hat{c}_{\alpha}$ is the best fit for the given calibration. For linear independent columns, a unique solution can be found by solving the normal equation:

$$
\begin{aligned}
\mathbf{K}^{T} K \cdot \hat{\boldsymbol{c}}_{\alpha} & =\mathbf{K}^{T} \boldsymbol{\alpha}, \\
\hat{\boldsymbol{c}}_{\alpha} & =\left(\mathbf{K}^{T} K\right)^{-1} \cdot \mathbf{K}^{T} \boldsymbol{\alpha} .
\end{aligned}
$$

Thus, the output of the wind-tunnel calibration are the coefficients $\boldsymbol{c}_{\alpha}, \boldsymbol{c}_{\beta}, \boldsymbol{c}_{\mathrm{s}}$ and $\boldsymbol{c}_{q}$.

\section{A2 Measurement with the multi-hole probe}

Once the probe has been calibrated, velocity and flow angles in arbitrary flows may be estimated as follows.

- The instantaneous pressures across each hole of the probe are converted to instantaneous $\Delta P, k_{\alpha}$, and $k_{\beta}$ according to Table 1 . 
- Subsequently, $\boldsymbol{k}_{p}, \boldsymbol{k}_{q}, \boldsymbol{\alpha}$ and $\boldsymbol{\beta}$ are estimated:

$$
\begin{aligned}
\boldsymbol{\alpha} & =\mathbf{K} \cdot \boldsymbol{c}_{\alpha}, \\
\boldsymbol{\beta} & =\mathbf{K} \cdot \boldsymbol{c}_{\beta}, \\
\boldsymbol{k}_{p} & =\mathbf{K} \cdot \boldsymbol{c}_{\mathrm{s}}, \\
\boldsymbol{k}_{q} & =\mathbf{K} \cdot \boldsymbol{c}_{q} .
\end{aligned}
$$

- Finally, the static pressure and the dynamic pressure are calculated solving the equations in Table 1 for $p$ and $q$, respectively.

Table A1. Calculation of static and dynamic pressure from five-hole probe measurements with two different methods.

\begin{tabular}{ccc}
\hline & Bohn et al. (1975) & Treaster and Yocum (1979) \\
\hline$p$ & $P_{\mathrm{S}}+\mathrm{d} P_{0 \mathrm{~s}}-k_{p} \cdot \Delta P$ & $P_{\mathrm{s}}+\Delta P-k_{p} \cdot\left(\mathrm{d} P_{0}-\Delta P\right)$ \\
$q$ & $\mathrm{~d} P_{0 \mathrm{~s}}+k_{q} \cdot \Delta P$ & $\mathrm{~d} P_{0}-k_{q} \cdot\left(\mathrm{d} P_{0}-\Delta P\right)$ \\
\hline
\end{tabular}

